It will be remembered that Prof. Newcomb communicated his principal result to the Royal Astronomical Society last summer (see "Monthly Notices," vol. xxxvi. p. 358).

Prof. Förster's Scientific Lectures. - Under the title Sammlzung wissenschaftlicher Vorträge, there has Jately appeared a series of seven lectures on astronomical subjects by the director of the Royal Observatory at Berlin. It includes an address on "The Astronomy of Antiquity and the Middle Ages in Relation to Modern Development," notices of Copernicus and Kepler and their works, \&c.

\section{CHEMICAL NOTES}

Variations in the Critical Point of Carbon Dioxide in Minerals, and Deductions from these and other FACTS.-Mr.W. N. Hartley has continued his experiments on this subject, and gives in a paper read lately before the Chemical Society further conclusions as to the existence of the expansible fluids in mineral cavities. He concludes it to be carbon dioxide from the spectrum produced by the electric spark in a tube containing such gas as was liberated by the decomposition of the minerals; the turbidity produced by crushing quartz under baryta water (Vogelsang and Geissler, 1869); the rate of expansion of the liquid in sapphire compared with that of carbon dioxide (Sorby and Butler, 1869) and the determinations of the critical point made by himself in $1875-76$. To determine the critical point he uses small thermometers made specially for the purpose, one having a range from -20 to $140^{\circ} \mathrm{F}$., the other graduated to register tenths of a degree from $25^{\circ}$ to $33^{\circ} \mathrm{C}$. The following table shows all the variations noticed in the critical point of carbon dioxide existing in various minerals :-

\begin{tabular}{lllll} 
& & \multicolumn{3}{c}{ Critical point. } \\
Topaz $\ldots$ & $\ldots$ & $\ldots$ & $\ldots$ & $28^{\circ} \mathrm{C}$. \\
Topaz $\ldots$ & $\ldots$ & $\ldots$ & $\ldots$ & $28^{\circ}$. C. and $26^{\circ} \cdot 5$ \\
Topaz $\ldots$ & $\ldots$ & $\ldots$ & $\ldots$ & $27^{\circ} \cdot 55$ \\
Tourmaline & $\ldots$ & $\ldots$ & $\ldots$ & $27^{\circ} \cdot 27$ \\
Tourmaline & $\ldots$ & $\ldots$ & $\ldots$ & $26^{\circ} \cdot 9$ \\
Sapphire & $\ldots$ & $\ldots$ & $\ldots$ & between $30^{\circ} \cdot 5$ and $31^{\circ}$ \\
Sapphire & $\ldots$ & $\ldots$ & $\ldots$ & between $25.5^{\circ}$ and $26^{\circ}$ \\
Sapphire & $\ldots$ & $\ldots$ & $\ldots$ & $29^{\circ} \cdot 5$ \\
Rock crystal & $\ldots$ & $\ldots$ & $\ldots$ & $30^{\circ} \cdot 95$ \\
Rock crystal & $\ldots$ & $\ldots$ & $\ldots$ & $30^{\circ} \cdot 95$ \\
Rock crystal & $\ldots$ & $\ldots$ & $\ldots$ & $32^{\circ} \cdot 5$ \\
Rock crystal & $\ldots$ & $\ldots$ & $\ldots$ & $33^{\circ} \cdot 7$ \\
Rock crystal & $\ldots$ & $\ldots$ & $\ldots$ & $39^{\circ}$ \\
Rock crystal & $\ldots$ & $\ldots$ & $\ldots$ & $30^{\circ} \cdot 9.5$ \\
Beryl $\ldots$ & $\ldots$ & $\ldots$ & $\ldots$ & $30^{\circ} \cdot 92$
\end{tabular}

He discusses, from his conclusions, certain ideas with regard to the formation of diamonds, and believes that it is difficult to suppose that they are entirely formed by a process in which unoxidised forms of carbcn are intermediate products, otherwise they would occur not unfrequently in the neighbourhood of coal formations. The theory that diamonds are produced by reducing agents on carbon dioxide very highly compressed and acted on at temperatures much above its critical point, introduces a condition of things highly suggestive of further speculation, and of experiments subject to conditions under which no chemical reactions have ever been made in the laboratory.

THermo-Chemical Researches.-Julius Thomsen has found in some recent investigations that gold presents allotropic modifications according to the nature of the solutions from which it is obtained, and the reagent with which it is precipitated. The modifications he has examined are gold precipitated from solution of the chloride and bromide respectively by sulphurous acis, and that precipitated from the sub-chloride, sub-bromide, and sub-iodide. These modifications differ in the amount of heat evolved by each in similar reactions. As the energy shown by the gold precipitated from solution of the chloride by sulphurous acid is less than in the other cases, this amount is taken as the standard. The energy of the gold precipitated from the bromide is greater by 3.200 theat units, and that precipitated from the sub-chloride, sub-iodide, or sub-bromide by 4.700 heat units per atom.

ThEINE IN TEA.-As the amount of theine varies in various kinds of tea (according to different analyses) from one to six per cent., the question naturally arises whether the quality of tea does not depend upon the amount of theine it contains. Some time ago $M$. Claus arrived at the conclusion that the inferior kinds of tea contain altogether more theine than the higher, pointing out especially that the cheapest, the so-called brick-tea used in Mongolia and Siberia, and prepared from all kinds of refuse as dead leaves, stalks, \&c., contains far more theine $(3 \cdot 3$ to 3.6 per cent.) than the higher qualities ( $\mathrm{r} \circ \mathrm{O}$ to $\mathrm{r} \cdot 3 \mathrm{per}$ cent.). M. Markovnikoff, of Moscow, now arrives at different ${ }_{1}^{2}$ results. Having made a series of analyses'of one kind of tea by the various analytical methods used until now, for ascertaining their comparative values, he proves the deficiency of most of these methods. Ether, for instance, extracts but one-thixd of the whole amount of theine, and benzole, one-fourth. Using, then, a more perfect method, and analysing six kinds of tea, selected from the highest and from the lowest qualities, he arrives at the result that the amount of theine in them varies but very little, from 2.08 to 2.44 , and that it regularly increases, with one exception, with the quality of tea, whilst the amount of ash given by each kind regularly decreases from 6.1 to $5 \%$ per cent. The differences being, however, very small, M. Markovnikoff supposes that the quality of tea does not depend, or depends very little, upon the amount of theine, and far more upon the quantity of tannic acid and aromatic oils it contains, but that on the whole the teas made from younger leaves contain more theine than those made from older leaves.

Influence of Pressure on Combustion.-Some interesting observations have been recently made by $\mathbf{M}$. Wartha, on the influence of pressure on combustion. $\mathrm{He}$ observed the burning of six stearine candles in free air, and in an iron case under a pressure of $x \cdot 95$ atmospheres. They burned under this pressure with a flame 9 to $12 \mathrm{~cm}$. long, and gave much smoke; their luminous power diminished, while the flame assumed a yellowish-red colour. The decrease of weight after one hour of burning was found to be less than in burning in free air. This last result is opposed to the observations of Frankland, who has affirmed that the consumption of the burning material of a candle, or the like, is not perceptibly dependent on the pressure of the medium in which the combustion occurs. It is supposed that the difference of pressure in Frankland's experiments (on Mont Blanc and at Chamounix) was not sufficiently great to give a distinct difference in consumption of the burning matter. M. Wartha further put a candle to burn under an airpump receiver, with special apertures, and, with increasing rarefaction, the flame was seen to enlarge, and its luminous power to diminish. At a pressure of $90 \mathrm{~mm}$., the greatest rarefaction produced, the luminous power was quite gone, and the flame, which had now assumed threefold size, appeared to consist of three parts, an inner bluish-green cone with a violet sheath, and a weakly violet mantle. The diminution of the luminous power in this case $\mathrm{M}$. Wartha explains by the fact that under less pressure less of the products of combustion are separated in the form of soot.

\section{BIOLOGICAL NOTES}

The American Bisons.-An important quarto memoir on the living and extinct Bisons of America, from the pen of Mr. J. A. Allen, has just been issued from the University Press of Cambridge, Massachusetts. It is illustrated by twelve plates and a map of North America, in which the distribution of the bison 
at different dates is indicated by various colours. The material for the account of the fossil forms, namely, Bison latifrons and $B$. antiquus, was obtained by Mr. N. S. Shaler, the Director of the Kentucky Geological Survey during I 868 and I869, at Big Bone Lick. Independent of its scientific interest the description of the chase and rapid diminution of the existing animal will be found well worthy of perusal.

Coloration of Water by SALPA.-Coral reefs, as is well known, give a greenish appearance to the surrounding water when they do not lie far below the surface of the sea. The captains of merchant-vessels are accustomed to report the observation of such spots in the ocean when they are not marked on the charts. It has, however, frequently occurred, that subsequent navigators are entirely unable to find at such points any trace of hidden reefs. Baron von Schleinitz, commander of the German vessel Gazelle, in the report on his late exploring expedition, mentions that he encountered ten such places in the meridian $177^{\circ} \mathrm{E}$. and $33^{\circ} \mathrm{S}$. The lead was sunk to distances varying from 400 to 600 feet, at all these places, without reaching bottom. The green water presented an appearance as if an oily liquid was constantly rising to the surface, and a quantity of it was secured for examination. Investigation showed the cause of the phenomenon to be the preserice of a great number of small, transparent, spherical salpæ. These were joined togsther in double rows of seve: each, and by imulaneous expansion and contraction maintained a regular and comparatively rapid motion.

The Evolution of The Camelidiz.- Prof. Cope traces an acceleration of the process of ossification of the cannon bones in Camelidx, by which the three constituent metapodials become united at earlier and earlier periods of life. In the oldest genus, Poëbrotherium, these bones are permanently distinct; they are long distinct in Procamelus; and in Auchenia the bones are united before birth. There has been a concurrent reduction of the incisor teeth. In the Soup Fork genus Protolabis the three superior incisors persisted throughout jife. In Pivcamelus occidentalis the second of these leeth persisted without being protruded till neariy adult age; the first incisor was very small, and, with its alveolus, was early removed. In the existing Camelidæ the second incisor disappears in the same way. In ruminants other than Camelidæ the third or external incisor has undergone the same process, while in the Bovidre the canines have also been atrophied.

Self-Fertilisation of Plants.-Mr. Thomas Mechan, continuing his observation: on this subject, has found that the flower o: Campanula pulcherrina, when coufined in fine gauze hags, seeded perfectly; the method of this self-fertilisation he has not discovered. He has observed the self-fertilisation of chicory, which has rather large white pollen grains. The whole process takes about two hours. About six o'clock in the morning the pistil with closed stigmatic lobes elongates, pushing through the mass of pollen, and carrying quantities with it. About an hour after the stigmatic lobes expand, and the pollen falls into the cleft and on to the stigmatic surface. The flowers close entirely by nine or ten o'clock of the same day. No doubt polleneating insects visited the flowers, but when these were carefully excluded, all the flowers had pollen on their stigmatic surfaces, nevertheless. (Proc. Acad Nat. Sci., Philaddpthia, i876, p. I42.)

an Unusual Case of Naturat Selection. - The usual causes for the origin and increase of secondary sexual characters do not exist among gasteropods; there is no struggling between the males for possession of the females. Mr. E. S. Morse has described (Proc. Boston Soc. Nat. Hist., 1876, p. 284) a curious case in which in a limited area the shelis of the males of Buccinum zindatzm scarcely equalled half the length of the female shells, and there was no doubt abont their maturity. The rocky ledge on which they lived was at all times washed by impetuous currents, and the specimens of Buccinum were always found hid in nooks and concealed in cracks and crevices. Only the smallest males could work their way into such constricted quarters to the females; thus a diminution of the normal size of the male had arisen from a singular secondary. sexual cause.

Gelatine in Relation to Nutrition.-Proceeding from the supposition that the processes of digestion are merely decompositions under the infuence of water, which furnishes smaller and more diffusible molecules, that are afterwards compounded into the constituents of the body, M. Hermann recently (Natur. forscher) proposed the question whether it might not be possible to employ gelatine for synthesis of albumen in the system (its decom. position products being very similar to those of albumen), merely adding tyrosin to it, the products of albumen-decomposition which are wanting. He accordingly requested M. Escher to make certain experiments on the subject. For a number of days the same food, containing gelatine but no albumen, was given to animals, and their weight and urine were determined. Then, for a similar number of days, the same amount of food was given, with a small quantity of tyrosin added, and weight and urine again determined. If the above supposition were correct, the bodyweight should diminish during the first period, and the excreted urine correspond to the golatine taken, plus some albumen of the body ; in the period in which tyrosin was given, the body-weight should decrease less quickly or not at all, or even increase, and the urine be diminished so much as would correspond to the quantity of gelatine retained in the body together with tyrosin, like albumen. The experiments (nine series of them) made on pigs and dogs gave the following results: $-\mathrm{r}$. Gelatine and tyrosin are absorbed in the intestine; they do not appear again in the excrement. 2. In food containing no albumen, gelatine alone cannot sustain the animal organism; the weight diminishes. 3. The same holds for tyrosin in food that is without albunen. 4. In food without olbuntn, gelatine and tyrosin may together sustain the organism; the weight of this remains stationary, or even increases. 5. The ardition of tyrosin to food containing gelatine, but no albumen, diminishes the excretion of urine, so that less nitrogen is excreted than taken.

\section{NOTES}

NEXX month a new mineralogical journal will appear in Ger. many to be called Zitscinreft fiur Krystallographie und Mineralogie. The cditor is Dr. Groth, Protessor of Mineralogy in the University of Strassburg. The most ewinent German and foreign mineralogists have promised their co-operation.

TH: Nation states that the Trustees of the Johns Hopkins University are prepared, if convinced of the want of such a periodical, to assist in the publication of an American Fournal of Pure and Applied Mathematics. A circular to elicit an expres. sion of views on this subject has been issued under the signatures of Professors J. J. Sylvester, Simon Newcomb, Henry A. Row. land, and William E. Story.

Messrs. Macmillan and Co. are about to publish the first volume of a "Treatise on Chemistry" by Prof. Froscoe and Dr. Schorlemmer. The aim of the authors in this work has been to furnish a concise but at the same time complete treatise, which they hope will serve as a standard for the use of those who desire to obtain a more extended knowledge than can be derived from the various excellent smaller manuals that exist. The authors endeavour to give as complete and accurate an account as possible of purely chemical phenomena, and a clear description of the chief chemical processes. In the case of each element and of the chief compounds a short historical statement of the 